\title{
MOOCs-The way to go
}

\author{
Shanta Rangaswamy ${ }^{1}$, Ramakanth Kumar $\mathrm{P}^{2}$, Uma B. ${ }^{3}$, Subramanya KN ${ }^{4}$ \\ ${ }_{1,2}$ Department of Computer Science and Engineering, \\ ${ }^{3}$ Department of Electronics and Communication Engineering, \\ ${ }^{4}$ Department of Industrial Engineering and Management' \\ ${ }_{1,2,3,4}$ Rashtreeya Vidyalaya College of Engineering \\ Bengaluru, India.
}

\begin{abstract}
MOOCs plays a vital role in transforming higher education across the globe. Today, providing an access to higher education to people of all sectors is the highest priority in all the developed and developing countries. Currently many universities in developed countries are able to get to the top rankings (by various agencies) because of their high education standards, flexibility in the education system, curriculum and outreach programmes. By this they are able to attract the best brains from across the globe. MOOCs helps them to attain this to a greater extent apart from the policy matters. In this paper, cumulative data of three consecutive years of a NPTEL local chapter and of courses in Coursera taken during the peak pandemic duration is taken in to consideration for the analysis of trends and popularity of MOOCs among students and faculty fraternity in a technical institution.
\end{abstract}

Keywords: MOOCs, Coursera, Online learning, Learner, SWAYAM

1. Introduction: Lifelong learning is a 'must' for a sustainable development of an individual as well as any Society. Because it is through this lifelong and sustainable development, one can continuously upgrade knowledge and acquire relevant skills required for livelihood opportunities, be it as an Employee, Employer or an Entrepreneur. Today, providing an access to higher education to people of all sectors is the highest priority in all the developing countries. Currently many universities in developed countries are able to get to the top rankings (by various agencies) because of their high education standards, flexibility in the education system and curriculum and outreach programmes. By this, they are able to attract the best brains from across the globe, be it as students or faculty members. However, in developing countries, the scenario is quite different. The unresolved issues like gender disparity, no or incomplete access to quality education, digital divide between the haves and have nots, and a wide gap in economic conditions, resists us in achieving high education standards. For a country to move from developing country to developed country, the growth of national income is a vital parameter. To achieve this the most and may be the only factor to be focused on is growth in knowledge economy and abundance of skilled and trained manpower.

For an online program to be successful, the curriculum, the facilitator, the technology and the students must be very carefully managed. This is required in order to take full advantage of the strengths of this mode of knowledge sharing and gaining, and at the same time to avoid the pitfalls that could result from its weaknesses. In this context, latest disruptive technologies like Massive Open Online Courses (MOOCs) and Open Educational Resources (OER) have a vital role to play. Massive Open Online Course (MOOC) is an emerging mode of education. MOOCs are already playing a major role in transforming higher education across the globe. In MOOCs, a teacher can teach thousands of students at the same time. It has become even more popular and relevant in this COVID-19 era. Online learning is no longer an option, it is a necessity. People have realized the importance and usefulness and ease of online learning. But the only challenge is of no live interaction with or among students. 
Today, everyone is talking about online education and sustainable education. Sustainable education would allow every human being to acquire the knowledge, skills, attitude, values and personality necessary to shape a sustainable future which in turn would bring long term benefits to all the individuals and a nation as a whole. Therefore, in order to ensure and promote sustainability in education, the differences in implementation of policies, gender gap, economic affordability and digital service availability need to be addressed first. MOOCs is one major platform which is and will be able to achieve this sustainable education. Different countries offer MOOCs through their own national platforms apart from Coursera and Edx. For example, it is J-MOOC in Japan, ThaiMOOC in Thailand, K-MOOC in Korea, OpenLearning.com in Malaysia and FutureLearn in UK. In the following sections, we have discussed about SWAYAM and Coursera, with the help of a dataset accumulated over a period of time of a technical institution.

2. SWAYAM in India: SWAYAM (Study Webs of Active-learning for Young Aspiring Minds) is a National MOOCs portal being developed by Ministry of Education, Government of India. It was initiated in the year 2006, with an intention to achieve the three major education policies, that is, Access, Equity and Equality. This is an online platform where the faculty members from eminent institutions like IITs, IIMs, IISc and Central Universities offer online courses. It is a consortium formed by nine National Coordinators such as NPTEL for Engineering, UGC for PostGraduation education, CEC for undergraduate education, NCERT And NIOS for school education, IGNOU for out-of-school students and IIMB for Management studies. This is done through a platform that facilitates hosting of all the courses, taught in classrooms from high school to post graduation level. This can be accessed by anyone, anywhere and at any time. SWAYAM is an integrated platform and portal for online courses. It provides an effective way of using
Information and Communication Technology (ICT). It covers courses from High School level to all higher education subjects, and skill sector courses to ensure that every student get benefits and privilege of learning material available through ICT. The objective of this initiative is to take the best teaching learning resources to all, including the most disadvantaged. It is a state of art system that allows easy access, monitoring and certification of all the courses it offers. They ensure that the quality of course contents produced and delivered through SWAYAM maintain high standards. Further, UGC and AICTE have already issued a regulation in the year 2016, that $20 \%$ of the total courses offered in a Programme by Indian Institutions/Universities could be released in the form of Credit framework via MOOCs (SWAYAM). This has changed the education scenario in the country. It has provided fast mobilization and dissemination of knowledge, skills and information among the prospective learners. A student is able to choose a course offered and map it to his/her curriculum subjects. Now they are able to learn at their own pace and the assessment is graded based on credit system. During this COVID 19 pandemic, AICTE is given the flexibility to Engineering colleges to offer $40 \%$ of their courses in any professional programmes through SWAYAM platform.

NPTEL: NPTEL (National Programme on Technology Enhanced Learning) is an official National Coordinator of SWAYAM for engineering courses. NPTEL has initiated certification process from the year 2014. It offers e-Learning through online web portal in Engineering, Science, Management and Humanities disciplines. These are run through 4 weeks, 8 weeks and 12-week courses. The list of number of courses offered are continuously updated every semester. Learners can enroll for any number of courses offered and start learning by listening to the lecture videos. They can interact with the peer group and also get the 
doubts related to the course clarified in the discussion forum. A learner needs to pay a nominal fee for Certification. Learners who satisfy minimum passing criterion earn a certificate from the IITs/IIsc/IISER, for the effort they have put in. UGC has also announced "Credit Framework for Online Learning Course through SWAYAM" regulations in 2016, wherein the credit transfer through SWAYAM courses is clearly defined. The advantage of participating and earning a certificate in an online course offered by NPTEL is that, a student can claim credit transfer (based on the regulations of the university/Institution). Apart from this, NPTEL also assist the toppers of the courses in getting Summer and Winter Internships. They also assist them in placement activities. NPTEL certificates earned by faculty members is considered as AICTE approved FDP for specific courses. For the working professionals it is a very exciting mode of upskilling and reskilling. At present, more than 4000 Engineering and Degree colleges in India are associated with NPTEL as a Local Chapter. NPTEL also offer Domain Certification. Recently, NPTEL has also initiated the text translation of its course contents in 8 different Indian languages. This has made MOOCs offered by NPTEL even more interesting and reach more learners.
Although online teaching learning and MOOCs are spoken of in a big way, challenges in adopting and implementing MOOCs in Indian scenario are: (i)Awareness among the general public about online learning methodologies available. (ii) Creditability of the certificates earned in real time scenario is not yet clear. (iii) The resistance among the teachers also to alter their teaching methodology from chalk-talk to techno-pedagogy (iv) Proper digital infrastructure for ICT based learning opportunities for the learners. This is not yet available to all the learners at all the times. (v) Not everybody is completely convinced with the usefulness of MOOCs and how it can exponentially increase the knowledge economy at a nominal cost.

A case study 1: Taking into consideration a data of past three years ( 6 semesters) of the number of learners registered for examination, number of toppers in either of the course, number of students and faculty members and the registered count, a simple data analysis was carried out. The data tabulated is of an Autonomous Institution which is one of the leading local chapter. This Local Chapter is rated as one among the top 100 institutions in all the previous semesters by NPTEL.

Table1: Sorted data semester wise

\begin{tabular}{|l|c|c|c|c|c|c|}
\hline & $\begin{array}{c}\mathbf{2 0 1 7} \\
\text { JAN-JUNE }\end{array}$ & $\begin{array}{c}\mathbf{2 0 1 7} \\
\text { AUG-DEC }\end{array}$ & $\begin{array}{c}\mathbf{2 0 1 8} \\
\text { JAN-JUNE }\end{array}$ & $\begin{array}{c}\mathbf{2 0 1 8} \\
\text { AUG-DEC }\end{array}$ & $\begin{array}{c}\mathbf{2 0 1 9} \\
\text { JAN-JUNE }\end{array}$ & $\begin{array}{c}\mathbf{2 0 1 9} \\
\text { AUG-DEC }\end{array}$ \\
\hline REGISTERED & 26 & 96 & 175 & 998 & 1012 & 458 \\
\hline TOPPERS & 3 & 17 & 36 & 123 & 80 & 46 \\
\hline STUDENTS & 24 & 76 & 156 & 954 & 951 & 413 \\
\hline FACULTY & 2 & 20 & 19 & 44 & 61 & 45 \\
\hline
\end{tabular}




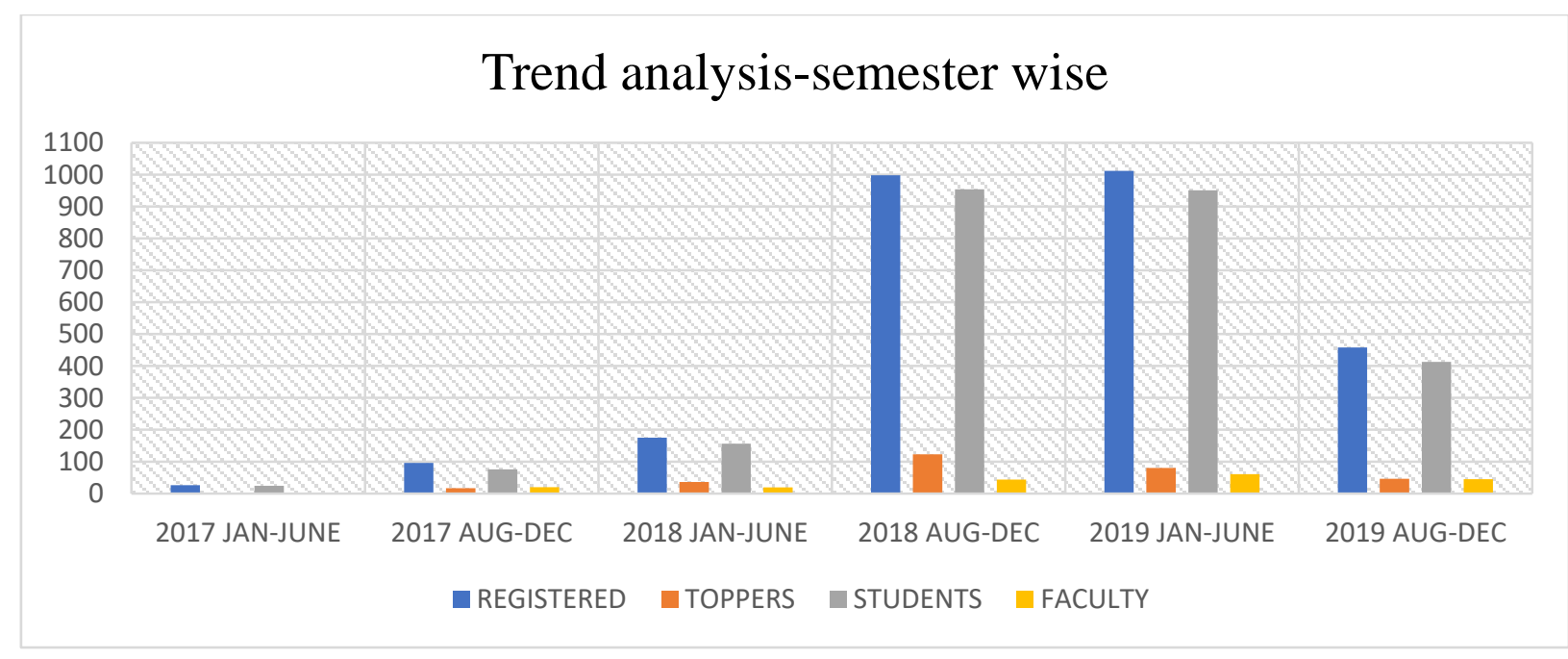

Graph 1: Semester wise data analysis

Graph 1 shows that the exam registrations have been increasing semester by semester positively, except the dip in Aug-Dec 2019 semester. This has picked up in the later semester. Also, though majority of the registered learners are students during all the six semesters, faculty involvement in the MOOC learning mode is slowly improving. The same is applicable to the count of toppers also. It is also found that the toppers list includes both students and faculty members. This is a very exciting trend, which means that MOOCs is being widely appreciated among the learners of all the age groups.

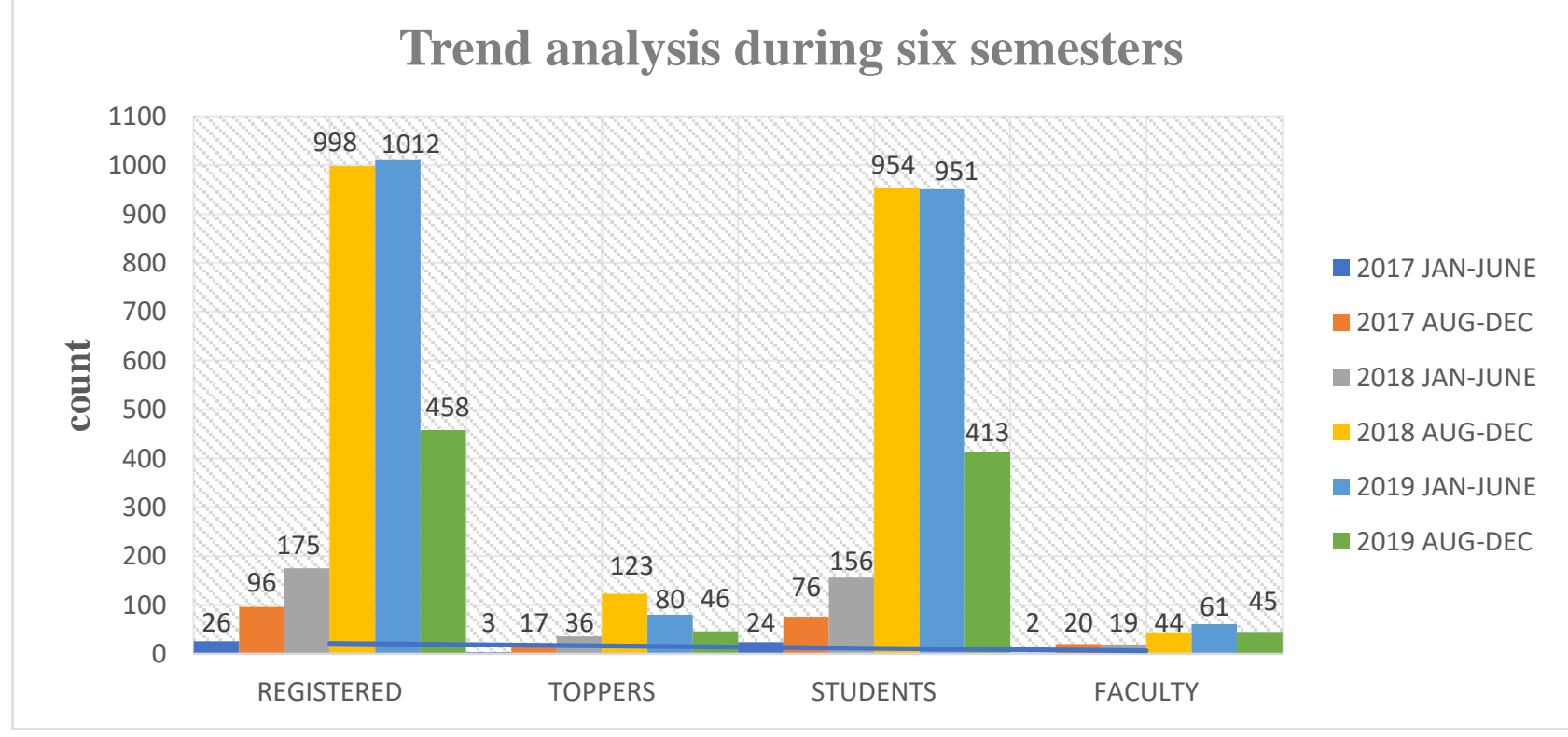

Graph 2: Semester wise data analysis

Graph 2 is the analysis carried out to identify the trend in the number of registered learners, number of toppers, number of student participation and number of faculty participation in NPTEL courses during six consecutive semesters. 


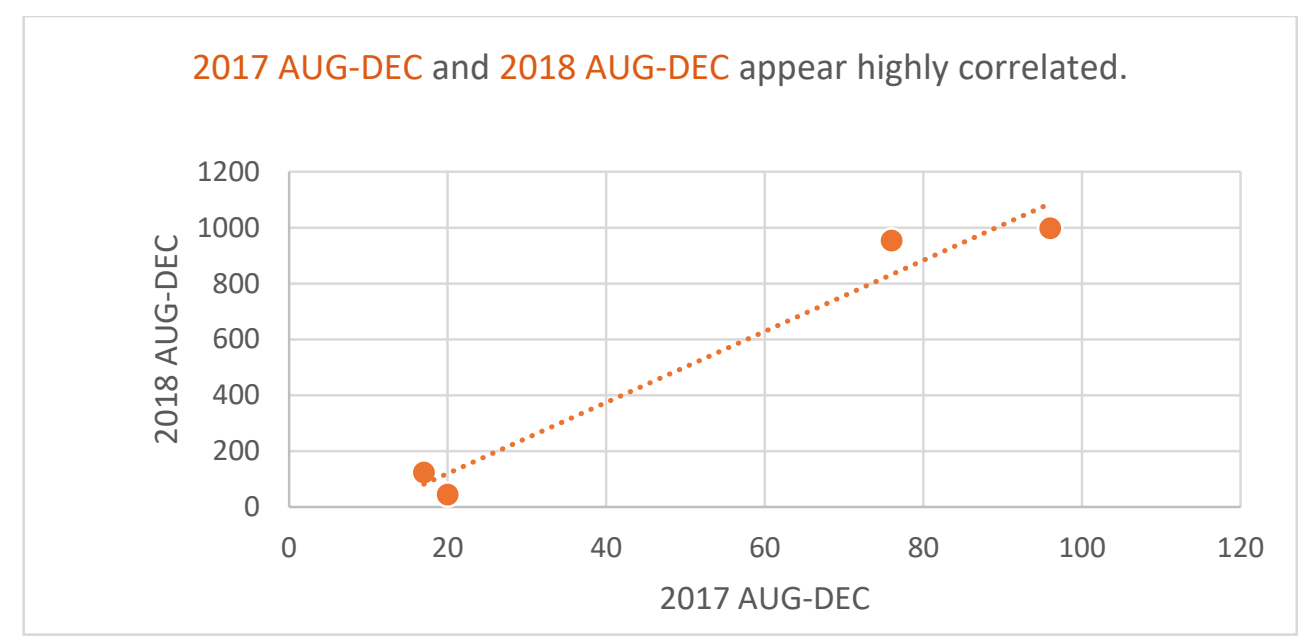

Graph 3: Correlation between Odd-Odd semesters

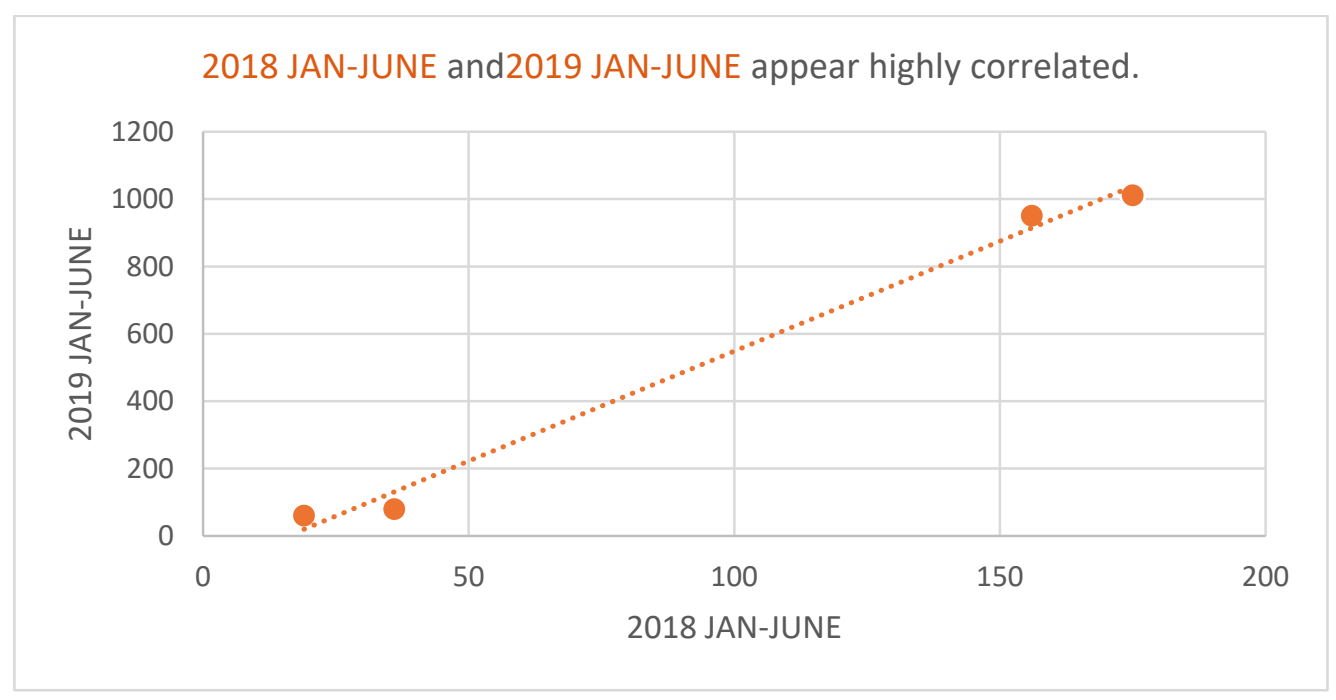

Graph 4: Correlation between Even-Even semesters

From the correlation graph 3 and graph 4 drawn between different semesters during the 2017-2019, it is found that the data is highly correlated between the odd-odd semester and even-even semester.

The inception of NPTEL offering e certificates from IISc and IITs is the major motivational factor for the learners. It is found that taking up these courses and performing well also boosts the student's internship and placement opportunities. Faculty members get a e-FDP certificate based on the course chosen. This is an AICTE approved certificate. The only challenge most of the student's face is when there is major mismatch between the calender of events of their institution and NPTEL.

III. Coursera: Coursera is an American MOOC provider founded in the year 2012 by Stanford University. It offers specialization, degrees and master track courses. Coursera has partnered with around 200 universities and companies for flexible and job-relevant online learning to individuals worldwide. Opportunities for hands-on projects are available. Here again courses are free to audit, but for access to graded assignments or to earn a certificate, 
a learner has to pay. These certificates hold considerable value with employers. If a learner earns a certificate for a course in a specialization certificate, it is an added weightage to his or her curriculum vitae. Coursera had launched free certification to around 3800 courses, during COVID19 pandemic, for a limited time. Many learners across the globe could productively make use of this opportunity, as it was a lockdown time everywhere.

A case study 2: The details of the course enrollment, completion and grades of the courses offered by Coursera were taken into consideration from the same institution. Coursera had offered few courses for free during the peak of COVID-19 pandemic. It is found that there was a drastic increase in the number of enrollments. Total enrollments during April 2020 to January 2021 throughout the institution was 1173.This includes students and faculty members from the institution. 477 learners had completed the different courses offered by Coursera and had scored more than $50 \%$ in the examination. The values tabulated in table 2 shows that many learners could score very well in the online courses of their choice. This could be because of the lockdown imposed during this time. Students could productively utilize the time available to them. Graphical representation of the same is depicted in graph 3 and graph 4 . It was found that $86 \%$ of the students have scored more than $90 \% .22 \%$ of the students have scored in the range of $90-99.95 \%$. Remaining students fall in the range of $50 \%$ to $70 \%$ score in the courses they had opted.

Table 2: Learners course grade in different margins

\begin{tabular}{|l|c|c|}
\hline Course Grade $(\boldsymbol{\%})$ & Count of Students & $\begin{array}{c}\text { Count of students in } \\
\text { Percentage }(\boldsymbol{\%})\end{array}$ \\
\hline 100 & 103 & 21.59 \\
\hline $99.95-90$ & 306 & 64.15 \\
\hline $89.75-80$ & 47 & 9.85 \\
\hline $78.02-70.09$ & 6 & 1.25 \\
\hline $68.53-60.37$ & 7 & 1.46 \\
\hline $58.51-50.92$ & 8 & 1.67 \\
\hline
\end{tabular}

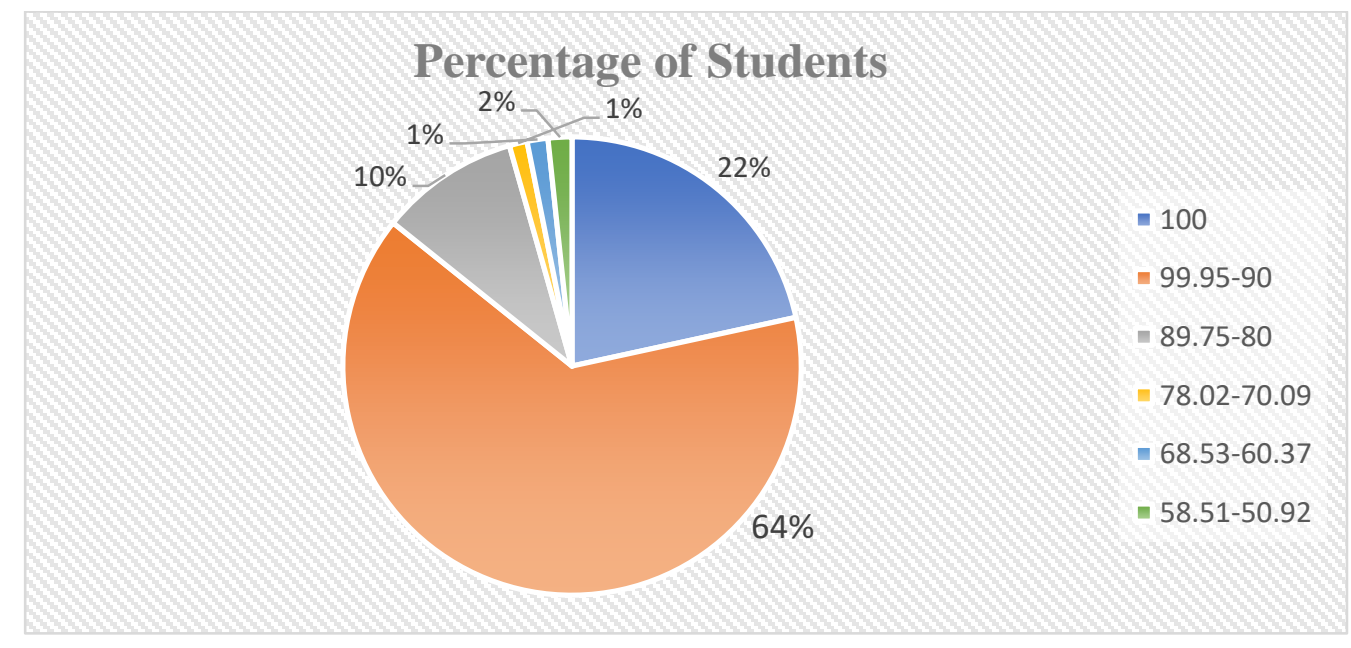

Graph 3: Percentage of students in different ranges of score 


\section{Count of Students}

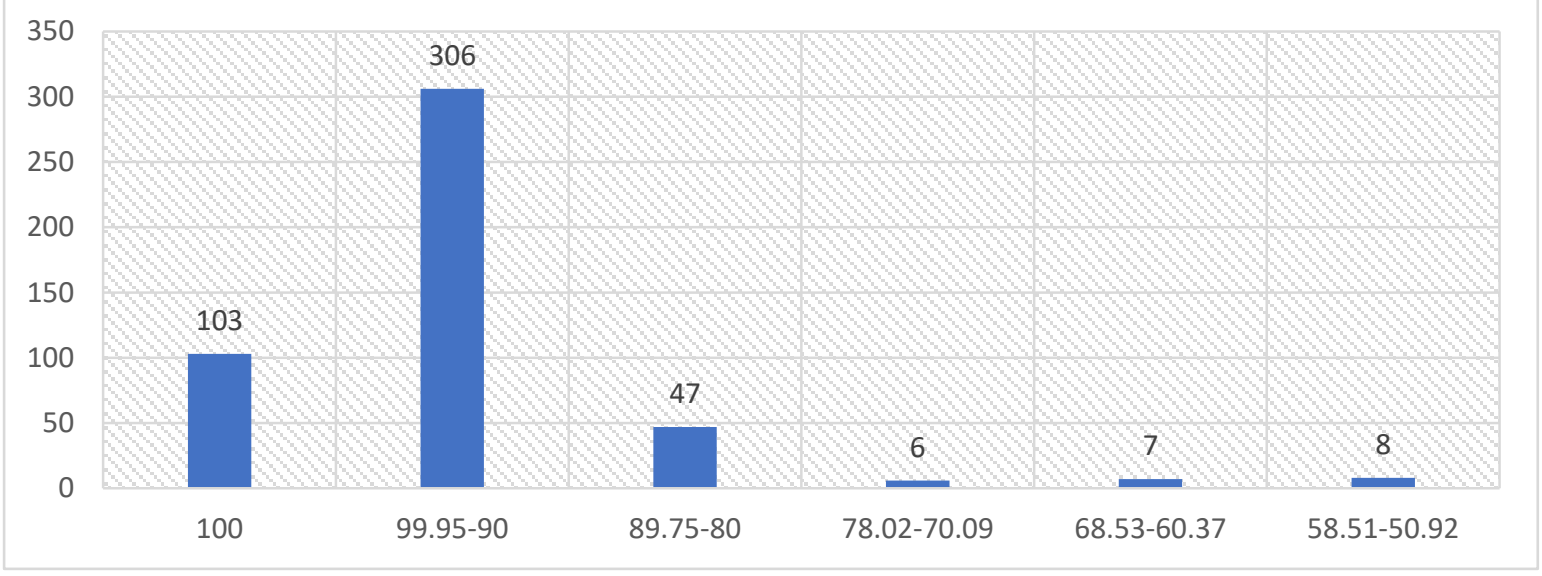

Graph 4: Count of students in different range of percentages

3. Discussion and Conclusion: MOOCs also caters to the academic institutions in attaining the Program Outcomes (PO) set by National Board of Accreditation (NBA). POs that are not directly associated with any particular course can be attained through MOOCs, especially PO7 and PO12 i.e., 'Environment and Sustainability' and 'Lifelong learning'. This is apart from other professional POs listed by NBA. MOOCs helps in overall development of a learner, makes him/her more career ready or job ready. Constant and sustainable improvement in Program Outcomes is directly reflected on the quality of students getting into a Programme every year.

In a way, MOOCs also helps the institution to defend a reasonable student teacher ratio. The issue of scarcity of quality faculty members in most of the institutions is also handled to some extend through MOOCs. Students also get to learn and interact directly through the professors from eminent institutions like IITs and IISc.

'Aatmanirbhar Bharat', an initiative by Government of India can be attained partially through MOOCs. Digital learning is skill based and develops the learner into a job/market ready professional. Learners choose the courses based on their interest, passion and need. This makes them more focused and responsible towards their career.

Challenges: With MOOCs in place the responsibility of certification and credit transfer now lies on the individual rather than the educational institute. Ratio of enrollments to course completion is very less. That means the dropout rate is high, as self-motivation to continue and complete the course is lacking among the learners. Having seamless internet access is still a challenge in few remote places. Wide economic inequality in few countries, also hampers the success of MOOCs. Awareness about MOOCs is not complete. At times few companies are not completely convinced of these certifications which a learner has earned independently. Collaboration and interactivity among the peer learners are still a challenge.

Thus, from the case studies it is quite evident that, MOOCs learners are from all walks of life, be it students or faculty members. Also, the learners have realized and recognized the importance of MOOCs in gaining knowledge and skill development. The advantage of learning anywhere, anytime is the main boon to the learners of this decade. The very fact that MOOCs removes the major 
challenges of time constraints or limitations with respect to travelling and age group related issues is an opening to education and better learning experience. In a way, issues related to color, gender and physical appearance among the learners also get sorted out automatically. With an easy availability and affordability of internet connectivity and smart phones, taking up an online course of our own choice is no longer a challenge. This integration of digital technology with education is transformational to the society. The freedom of anytime, anywhere is THE boon to the learners. All in all, it is clear that MOOCs has democratized learning.

\section{References:}

Dutta, A. (2020). Impact of digital social media on Indian higher education: alternative approaches of online learning during COVID-19 pandemic crisis. International journal of scientific and research publications, 10(5), 6046011.

Hassan, M. M., Mirza, T., \& Hussain, M. W. (2020). A Critical Review by Teachers on the Online Teaching-Learning during the COVID19 [J]. International Journal of Education and Management Engineering, 10(8), 17-27.

Bordoloi, R., Das, P., \& Das, K. (2020). Lifelong learning opportunities through MOOCs in India. Asian Association of Open Universities Journal.

Adnan, M., \& Anwar, K. (2020). Online Learning amid the COVID-19 Pandemic: Students' Perspectives. Online Submission, 2(1), 45-51.

Dhawan, S. (2020). Online learning: A panacea in the time of COVID-19 crisis. Journal of Educational Technology Systems, 49(1), 5-22.

Kasch, J., van Rosmalen, P., Löhr, A., Klemke, R., Antonaci, A., \& Kalz, M. (2021). Students' perceptions of the peer-feedback experience in MOOCs. Distance Education, 42(1), 145-163.
Masters, K. (2011). A brief guide to understanding MOOCs. The Internet Journal of Medical Education, 1(2), 2.

Griffiths, M. A., Goodyear, V. A., \& Armour, K. M. (2021). Massive open online courses (MOOCs) for professional development: meeting the needs and expectations of physical education teachers and youth sport coaches. Physical Education and Sport Pedagogy, 1-15.

Julia, K., \& Marco, K. (2021). Educational scalability in MOOCs: Analysing instructional designs to find best practices. Computers \& Education, 161, 104054.

Cagiltay, N. E., Cagiltay, K., \& Celik, B. (2020). An Analysis of Course Characteristics, Learner Characteristics, and Certification Rates in MITx MOOCs. International Review of Research in Open and Distributed Learning, 21(3), 121-139.

Alonso-Mencía, M. E., Alario-Hoyos, C., Maldonado-Mahauad, J., Estévez-Ayres, I., Pérez-Sanagustín, M., \& Delgado Kloos, C. (2020). Self-regulated learning in MOOCs: lessons learned from a literature review. Educational Review, 72(3), 319-345.

Deng, R., Benckendorff, P., \& Gannaway, D. (2020). Learner engagement in MOOCs: Scale development and validation. British Journal of Educational Technology, 51(1), 245-262.

Gamage, D., Perera, I., \& Fernando, S. (2020). MOOCs Lack Interactivity and Collaborativeness: Evaluating MOOC Platforms. iJEP, 10(2), 94-111.

Muthukumar, V., \& Bhalaji, N. (2020). MOOCVERSITY-Deep Learning Based Dropout Prediction in MOOCs over Weeks. Journal of Soft Computing Paradigm (JSCP), 2(03), 140152.

Zalli, M. M. M., Nordin, H., \& Hashim, R. (2020). Online Self-Regulated Learning Strategies in MOOCs: A Measurement 
Model. International Journal of Emerging

Technologies in Learning, 15(8), 255-263. 